\title{
Development and Operation of an Automatic Rotor Trim Control System for the UH-60 Individual Blade Control Wind Tunnel Test
}

\author{
Colin R. Theodore \\ NASA Ames Research Center \\ Moffett Field, CA
}

\author{
Mark B. Tischler \\ Aeroflightdynamics Directorate (AMRDEC) \\ U.S. Army RDECOM \\ Moffett Field, CA
}

\begin{abstract}
An automatic rotor trim control system was developed and successfully used during a wind tunnel test of a full-scale UH-60 rotor system with Individual Blade Control (IBC) actuators. The trim control system allowed rotor trim to be set more quickly, precisely and repeatably than in previous wind tunnel tests. This control system also allowed the rotor trim state to be maintained during transients and drift in wind tunnel flow, and through changes in IBC actuation. The ability to maintain a consistent rotor trim state was key to quickly and accurately evaluating the effect of IBC on rotor performance, vibration, noise and loads. This paper presents details of the design and implementation of the trim control system including the rotor system hardware, trim control requirements, and trim control hardware and software implementation. Results are presented showing the effect of IBC on rotor trim and dynamic response, a validation of the rotor dynamic simulation used to calculate the initial control gains and tuning of the control system, and the overall performance of the trim control system during the wind tunnel test.
\end{abstract}

\section{Introduction}

A wind tunnel test was recently completed in the National Full-Scale Aerodynamic Complex (NFAC) 40by 80 -foot wind tunnel to assess the rotor performance, vibration and acoustics benefits that could be obtained with an Individual Blade Control (IBC) system (Ref. 1). A key element of this wind tunnel test was the operation of an automatic rotor trim control system to allow the operator to set a precise and repeatable trim condition, and to automatically maintain the desired trim condition through changes in IBC actuation. This work represents the first time an automatic rotor trim control system has been used for rotor testing in the NFAC wind tunnels.

Previous wind tunnel experiments with IBC systems (Ref. 2-4) have shown the potential to reduce noise and vibration, and reduce power required and improve overall rotor performance with IBC actuation. However some of these results are questioned because of uncertainties in setting the same rotor trim condition with IBC actuation as that used for the baseline condition (without IBC). To illustrate the effect of IBC actuation on rotor trim, figure 1 shows example time history data collected during the current wind tunnel test for a $2 / \mathrm{rev}$ IBC phase sweep. For these data, the $2 /$ rev phase was changed every 15 seconds in 30 degree increments from a phase of 0 degrees at the start to 360 degrees at the end and the swashplate is fixed (no trim control). It is clear that these data alone would not give an accurate measure of the effect of IBC on rotor performance because of the differences in rotor operating conditions, in particular lift and propulsive force. Previous tests have tried to account for this by manually re-trimming the rotor following each change in IBC phase, which was time consuming and difficult, and still raised questions

Presented at the American Helicopter Society Specialists' Conference on Aeromechanics, Fisherman's Wharf, San Francisco, CA, January 20-22, 2010. This is a work of the U.S. Government and is not subject to copyright protection. 
about achieving a common trim condition (Ref. 2). An automatic trim system that can repeatably trim the rotor to desired conditions and maintain the trim through changes in IBC actuation, such as described in this paper, addresses these questions.

An additional effect that must be accounted for is variation in wind tunnel flow that affects the rotor loading. Figure 2 shows example time history data collected during the current wind tunnel test with the swashplate fixed (no trim control) and no IBC actuation. This figure shows that there is some low frequency drift in the wind tunnel flow which effects the rotor forces and moments and one way to overcome this is with an automatic system.

This paper provides an overview of the development and operation of the trim control system used in the $\mathrm{UH}-60 / \mathrm{IBC}$ wind tunnel test. The first section of this paper gives an overview of the wind tunnel test hardware and the rotor control system hardware. The next section describes the design and implementation of the trim control system, including: the trim control operational modes and functionality, hardware and software architecture, operator interface, inner-loop control architecture and calculation of initial control loop gains, and the trim control procedures used during the wind tunnel test. Results are presented that show the effect of IBC actuation on the rotor dynamic response and a comparison of the rotor dynamics measured in the wind tunnel and those predicted using a simulation mode. Final results show the performance of the trim controller during testing and compare the final tuned gains with the initial calculated gains.

\section{Wind Tunnel and Rotor System Hardware}

The trim control system described in this paper was used as part of the UH-60 IBC wind tunnel test (Ref. 1) conducted in the National Full-Scale Aerodynamics Complex (NFAC) 40- by 80-foot wind tunnel located at NASA Ames Research Center. The rotor system was a full-scale Sikorsky UH-60A rotor hub assembly mounted on the Large Rotor Test Apparatus (LRTA). The LRTA is a special test rig designed to test helicopter rotors in the NFAC and consists of a rotor drive system, rotor balance, and rotor swashplate control systems. The LRTA was mounted on three struts allowing an angle-of-attack range of 0 degrees to -15 degrees. Angle-of-attack, or shaft angle, variations were controlled manually by a wind tunnel operator during the wind tunnel test. A sensor was used to measure the strut length, which was inturn translated into a rotor shaft angle measurement. Figure 3 shows the model installed in the wind tunnel. Additional details of the LRTA, wind tunnel installation and UH-60A rotor hardware can be found in Refs. 1-3.

For this particular wind tunnel test, the normally rigid pitch links of the rotor were replaced with servohydraulic actuators that allow the root pitch of each blade to be changed independently. The actuators were developed by ZF Luftfahrttechnik (ZFL) and are capable of producing perturbations in blade pitch up to $+/-6.0$ degrees and up to frequencies above $7 /$ rev. A full description of the actuator characteristics is provided in Ref. 5. The IBC actuators were driven with both open-loop and closed-loop inputs to evaluate their potential to improve rotor performance; to reduce vibration, loads, and noise; and to perform reconfiguration and in-flight tuning tasks. The closed-loop controllers included both adaptive and non-adaptive algorithms using open-loop recursive system identification to estimate the plant model for the initialization of these closed-loop algorithms.

\section{Rotor Swashplate Control Hardware}

Rotor swashplate control on the LRTA is provided through three identical actuator assemblies, each of which includes a primary actuator and a dynamic actuator mounted in series to provide total swashplate actuation. The primary actuators are high-authority/low-speed linear electric actuators that provide primary rotor collective and cyclic swashplate control and are controlled by the rotor operator through the 
Primary Control Console (PCC). The rotor operator trims the rotor based on displays of the rotor force and moment coefficients, and the rotor longitudinal and lateral flapping.

The dynamic actuators are high-speed rotary-hydraulic actuators that provide low-authority, highbandwidth control of the swashplate position about the nominal angle set by the PCC. The dynamic actuators are controlled by time-varying commands from the Dynamic Control Console (DCC). For this test, the Trim Control System supplies time-varying swashplate perturbation commands to the DCC, which in-turn drives the dynamic actuators. To ensure that the dynamic actuators are not driven to their physical hardware limits, each actuator is fitted with limit switches. When a limit switch on one of the actuators is reached, a hardware lockout is activated that rapidly forces all of the dynamic actuators to their neutral (or zero) positions and lock the actuators in this position. For this test, the limit switches were set to allow a collective (all actuators moving together) range of about $+/-2$ degrees. These limit switches and hardware lockout mechanism provides a level of safety and physically limits the authority of the dynamic swashplate system.

Figure 4 shows a simplified block diagram of the three different controls for the rotor blade pitch angles. The 'Manual Trim Inputs' block refers to the rotor operator inputs through the PCC, The 'Rotor Trim Controller' block refers to the trim control commands through the DCC, and the 'IBC Actuator Commands' control pitch angle perturbations in the rotating frame to the individual blades.

\section{Rotor System Instrumentation and Data Transfer}

The transfer of LRTA rotor system measurements and engineering unit data to the trim control and IBC control systems is performed by the Data Transfer Computer (DTC), as shown in Figure 4. The DTC acquires analog data, computes engineering unit and derived parameters, corrects these measurements for aerodynamic and weight tares, and provides derived data in analog form to the IBC and trim control systems. The DTC is a National Instruments RT-based system that processes data at 256 samples/rev, or about $1100 \mathrm{~Hz}$ at a nominal rotor speed of $258 \mathrm{RPM}$. The derived data provided to the trim control system included the rotor balance forces and moments in the hub axis system.

\section{Trim Control System Design and Implementation}

This section describes the development and implementation of the trim control system used as part of the IBC wind tunnel test. This includes a description of the trim controller operational requirements that drive the design, the hardware and software architecture, the inner-loop control architecture and calculation of initial gains, the operator interface, and the procedures used to trim the rotor during the wind tunnel test.

\section{Trim Controller Operational Modes and Functionality}

Two main trim control methods or modes were built into the rotor trim controller. Both of these methods use swashplate collective and lateral cyclic to control the rotor lift and rolling moment, but differ in how they control the propulsive force and the feedback quantity for the longitudinal cyclic channel.

Trim Control Mode 1 controlled the rotor lift and hub pitching and rolling moments through swashplate collective, longitudinal cyclic, and lateral cyclic pitch changes through the swashplate dynamic actuators. The rotor propulsive force was controlled through changes to the model shaft angle that were implemented manually. The trim controller calculated the shaft angle change required to obtain the desired propulsive force based on a look-up table of the propulsive force sensitivity to shaft angle change. Typically one or two shaft angle change iterations were required to converge on the desired rotor propulsive force. 
Trim Control Mode 2 controlled the rotor lift, propulsive force and hub rolling moment through the threeswashplate controls (note that the hub pitching moment was not controlled). This trim method was performed with the shaft angle fixed since the rotor propulsive force was controlled directly through swashplate inputs. This trim strategy of controlling propulsive force primarily with longitudinal cyclic is more challenging than trim control mode 1 where pitching moments is controlled with longitudinal cyclic. This is because propulsive force is not the primary rotor response to longitudinal cyclic and is achieved through changes in rotor longitudinal flapping. This results in a higher response delay of propulsive force response in trim control mode 2 than the pitching moment response in trim control mode 1.

Both of the force and moment trim methods were effective at controlling rotor trim, but the second method was more time effective since the rotor was trimmed and re-trimmed in a matter of seconds without requiring any shaft angle changes. For this reason, the majority of research data collection during the wind tunnel entry was performed using trim mode 2 .

In addition to these trim control modes, the trim control system included a frequency sweep (chirp) generator function that could be applied to any of the three-swashplate controls. Functionality was also included that allowed the operator to switch back and forth between the trim control active or "continuous" mode, and a "fixed" mode where swashplate commands would be the average over the previous 10 seconds. The trim controller included software limits on the swashplate commands from the trim controller (set between 1 and 2 degrees). When these software limits were reached, the swashplate commands would ramp to zero.

The trim control system also included data acquisition, reduction and analysis capabilities. The trim control system cycled at $100 \mathrm{~Hz}$ and continuously acquired data at this rate for each test run (up to 3-4 hours). Recorded data included all input and output voltage and engineering unit channels, and internal trim control parameters used for development and validation of the controller.

\section{Trim Control System Hardware and Software Architecture}

All of the functionality of the Trim Control System, include the inner-loop trim control, mode switching and frequency sweep generation, were written in Matlab $^{\circledR}$ Simulink $^{\circledR}$. Figure 5 shows the top level of this block diagram. The blocks highlighted in blue contain the trim control configuration, mode switching, and operation functions, and also process the digital signals from the analog-to-digital converters into engineering units. The blocks in orange contain the trim command signal conditioning, inner-loop control laws, swashplate control limiting, and frequency sweep generation functions. The blocks in green are used for trim controller development and Hardware-In-the-Loop (HIL) simulation and contain models of the swashplate actuator dynamics and control mixing, rotor dynamics, and representative levels of $1 / \mathrm{rev}, 4 / \mathrm{rev}$ low frequency drift and noise on all of the rotor response channels to simulate wind tunnel measurements. The levels of vibration, drift and noise were set based on analysis of some early wind tunnel data. These simulation blocks are always active, but their outputs are only used for trim control development and HIL simulation. Finally the block in magenta processes the engineering unit data to signals for the digital-to-analog converters on the right hand side.

The Simulink block diagram was compiled into an executable Dynamic Linked Library (DLL) using the Matlab Realtime Workshop toolbox. This executable library was imported into National Instruments LabView and uploaded to the trim control hardware, which is a National Instruments PXI-1042Q realtime system with a PXI-8106 Embedded Controller. The inputs to the trim controller (hub forces and moments from the DTC) were digitally low-pass filtered at $6 \mathrm{~Hz}$ to remove the high-frequency rotor harmonic and vibration content before being used as feedback for the trim controller. The trim controller cycled at $100 \mathrm{~Hz}$, continually updating the swashplate commands that are sent to the dynamic actuators through the DCC. An operator interface to the trim controller was developed using LabView and runs on a separate desktop PC connected to the trim control hardware system with an Ethernet cable. 
More detail on the inner-loop control architecture, calculation of initial control system gains and operator interface is provided in the following sections.

\section{Trim Control Inner-Loop Architecture}

The inner-loop of the control system calculates swashplate control inputs based on the differences between the desired and measured rotor forces and moments. The inner-loop control architecture for each of the trim control methods described above used proportional and integral (PI) control in each of the three-swashplate control channels. A pseudo-derivative or washout filter is included in each channel since there is no direct measurement of the derivative of the hub forces and moments that can be used with a derivative gain. The pseudo-derivative filter provides lower frequency derivative control action without significant amplification of high-frequency noise.

Cross-feeds were included in the control system between the swashplate collective pitch and longitudinal cyclic pitch inputs to account for coupling between rotor lift and pitching moment in trim control mode 1 and rotor lift and propulsive force in trim control mode 2.

\section{Calculation of Initial Control System Gains}

Initial sets of control law gains were calculated using the Control Designer's Unified Interface $\left(\right.$ CONDUIT $^{\circledR}$ ) program (Ref. 6 ) based on a set of stability, performance and disturbance rejection specifications, and simulation models of the rotor dynamics. The rotor dynamics models were obtained using the FORECAST simulation code (Ref. 7) and were represented in linear state-space form. These linear models included 8 states for rigid blade flapping, 8 states for rigid blade lead-lad, 3 states for linear dynamic inflow, and 2 states for blade dynamic twist. Gain sets were calculated for each of the trim control modes and at a number of different forward speeds and rotor loading conditions. During initial testing and gain tuning of the trim controller in the wind tunnel it was found that two sets of control law gains for each trim control mode were sufficient to cover the entire speed and loading test envelope. The first gain set was used for speeds up to 120 knots with initial gains based on the CONDUIT ${ }^{\circledR}$ analysis at a speed of 80 knots and a lift of 18,000 pounds (equivalent to $1 \mathrm{~g}$ flight). The second gain set was used for speeds above 120 knots with initial gains calculated at a speed of 160 knots and a lift of 18,000 pounds.

Figure 6 shows an example of the CONDUIT ${ }^{\circledR}$ Handling Qualities window (for the high-speed case at 160 knots and trim control mode 2) that shows the control system specifications used to calculate the control system gains. Two key sets of specifications are the control system stability margins and the disturbance rejection characteristics. The stability margins for the trim control system in both modes 1 and 2 well exceed the standard requirements of $6 \mathrm{~dB}$ of gain margin and 45 degrees of phase margin.

The disturbance rejection characteristics of the control system are represented by the disturbance rejection sensitivity function that gives the disturbance rejection performance of the control system as a function of frequency. Figure 7 shows the disturbance rejection sensitivity function for propulsive force control using longitudinal cyclic. The two important parameters on this plot are the disturbance rejection bandwidth and the disturbance rejection peak (Ref. 8). The bandwidth is defined by the frequency of the $3 \mathrm{~dB}$ crossing and indicates that disturbances below this frequency will be attenuated by at least $45 \%$ ($3 \mathrm{~dB})$. For this case, the disturbance rejection bandwidth is at a minimum of $1.0 \mathrm{rad} / \mathrm{sec}$, which is also typical for helicopter flight control in free flight (Ref. 9). The disturbance rejection peak indicates the maximum amplification of disturbances that would be expected with this control system. For this particular case, the disturbance rejection peak is $2.36 \mathrm{~dB}$, which corresponds to an amplification of below $30 \%$.

Figure 8 shows the closed-loop time histories of propulsive command and response for a step command. This shows that overall the system is well damped with a quick response and no low frequency overshoot 
or oscillation. This plot also shows that there is a high frequency oscillation at about $5.5 \mathrm{~Hz}$ in the propulsive force response that damps out quickly by about 2 seconds. This oscillation is due to the excitation of the progressive lag mode that essentially produces an in-plane rotation of the rotor center of gravity that results in an oscillation of the propulsive force at the progressive lag mode frequency. This effect is illustrated in figure 9 that shows how the fixed-frame lag mode couples into the propulsive force.

Figure 10 shows the FORECAST prediction of progressive lag mode damping as a function of speed at two different loading conditions. This shows that the modal damping decreases at higher speeds indicating that the mode will have a greater coupling with propulsive force. In wind tunnel testing, this oscillation was reduced by adding a notch filter on the propulsive force feedback signal at the progressive lag mode frequency. This will be discussed further in the next section. It should be noted that this notch filter was only required for the high-speed case and trim control mode 2 that used direct feedback of propulsive force. The notch filter was not required for trim control mode 1 since the progressive lag mode and associated in-plane rotor center of gravity oscillations did not couple into the lift or pitching and rolling moments.

Figure 11 shows an example of how the cross-feed values in the control system are chosen. This figure shows the responses of propulsive force (black) and lift force (with different cross-feed values) to a step command of propulsive force. The cross-feed value is adjusted until a minimum amount of lift force response is generated, as is shown in blue for this case with a cross-feed value of 5.0.

\section{Trim Controller Operator Interface}

The trim control operator interface was developed using the National Instruments LabView software, which provides a set of tools to efficiently design, implement and modify user interfaces. Figure 12 shows a screenshot of the final trim control operator interface. The interface allows the operator to control and monitor all aspects of the trim control system including the controller configuration and mode switching, specification of trim set point, and frequency sweep generation. Across the top of this interface in Figure 12 are the key operational switches for the trim controller includes the trim mode selection, switching between 'continuous' to 'fixed' modes, activation of the frequency sweep generator and termination of trim operation. Indicators along the top of the interface also display the current status of the trim control system. On the left are the trim set points, displays of measured rotor loads in numeric and strip-chart forms, and the dynamic swashplate commands sent to the LRTA DCC. On the right the operator can view and set the control law gains, swashplate software limits, and signal processing filtering options. Additional tabs allow the operator to set the frequency sweep characteristics (swashplate input channel, frequency range, control amplitude, sweep time, etc.), and D-A and A-D bias and scale parameters as necessary. LabView provides functionality to read in a data file that automatically populates predefined sets of fields on the operator interface. This functionality was used to load in different gain sets depending on the test condition.

\section{Rotor Trim Procedures}

The procedure to trim the rotor system during this test involved coordination between the rotor operator, who controlled the swashplate primary actuators through the $\mathrm{PCC}$, and the trim control system operator, who controlled the swashplate dynamic actuators through the trim control system and DCC. The basic procedure was to first have the rotor operator get close to the desired condition using the primary swashplate actuators. The desired trim condition in terms of the rotor lift and propulsive force, and hub pitching and rolling moment values were entered into the trim controller operator interface and the trim controller was activated in 'continuous' mode to drive the swashplate dynamic actuators to refine the rotor trim to the desired condition. The trim controller continually updated the swashplate commands to maintain the desired trim condition through changes in IBC actuation and long-period transients in wind tunnel flow. 


\section{Results}

This section presents results for the tuning, performance and validation of the automatic trim control system used during the UH-60 IBC wind tunnel test. First is a discussion of the tuning of the control law gains during initial wind tunnel testing and the performance of the trim controller during research data collection. Results are presented primarily for trim control mode 2 in high-speed data runs. This is the most challenging control configuration and test condition with propulsive force being controlled primarily with longitudinal cyclic and lower damping of the progressive lag mode at high speed. The next set of results show a validation of the control system design and optimization process and show the effects of IBC actuation on the rotor dynamic response and a comparison between the wind tunnel model responses and the FORECAST simulation model responses. Final results show a CONDUIT ${ }^{\circledR}$ analysis of the final high-speed gain set for trim control mode 2 .

\section{Trim Control Gain Tuning}

Initial wind tunnel testing with the trim control system focused on tuning the control law gains at the various test conditions to get the desired performance. It was found that only two sets of control law gains for each trim control mode were needed to cover the entire speed and loading test envelope. The first gain set was used for speeds up to 120 knots with initial gains based on the CONDUIT ${ }^{\circledR}$ analysis at a speed of 80 knots and a lift of 18,000 pounds (equivalent to $1 \mathrm{~g}$ flight). The second gain set was used for speeds above 120 knots with initial gains calculated at a speed of 160 knots and a lift of 18,000 pounds.

Gain tuning consisted of adjusting the cross-feed between the collective and longitudinal cyclic channels until the off-axis response was minimized, and raising and lowering the control law gains until the desired closed-loop performance was reached. To simplify the process of tuning the inner-loop gains, a gain multiplier was adjusted to scale all gains equally, from an initial value of 1 . This process was considerably faster than attempting to tune each of the gains, or control channels individually, and still produces good trim control performance. For the high-speed case and trim control mode 2, the gains were reduced to $60 \%$ of the baseline values to get good stable performance with no oscillations and the cross-feed value was lowered from 5.0 to 3.0 to give the lowest lift response for longitudinal cyclic inputs. Similar gain reductions were made for the lower-speed controllers and with trim control mode 1.

In addition to adjusting the control gains, it was necessary to add a notch filter in the propulsive force feedback channel at the progressive lag mode frequency of $5.67 \mathrm{~Hz}$ when using trim control mode 2 with the high-speed gains. This notch filter effectively removed the coupling between longitudinal cyclic and propulsive force that was producing an oscillation. This oscillation was not seen when operating in trim control mode 1 at high-speed since the excitation of the progressive lag mode did not contribute to the pitching moment response. Also at lower speeds with trim control mode 2, the progressive lag mode has sufficient damping to quickly attenuate any oscillations.

\section{Final Trim Control Performance}

Both of the trim control methods developed for this wind tunnel test were effective at accurately trimming the rotor through transients in wind tunnel flow and IBC actuation over the entire wind tunnel speed and rotor loading test envelope used in this wind tunnel entry. The shaft fixed controller with direct propulsive force control (trim control mode 2) was more time efficient and was used for the majority of the research data collection. This is also the only trim control mode that could be used with the IBC system in automatic open-loop or closed-loop modes.

Figure 13 shows a comparison between the rotor forces and moments with and without trim control (without $\mathrm{IBC}$ ). These data were taken at an advance ratio of 0.35 and a lift of about 18,000 pounds. The time histories on the left are with the trim control system turned off, and the time histories on the right are 
with the trim controller operating in mode 2. Without trim control, there is some low frequency variability in the loads measurements due to transients in wind tunnel flow. With the trim controller active, the lift and propulsive forces are held more uniform and are centered around the desired trim condition, but show more higher frequency content than for the baseline case. This is consistent with the disturbance rejection characteristics of the controller where there is some amplification of the disturbances at frequencies above about $1.2 \mathrm{rad} / \mathrm{sec}$. Another important observation from Figure 13 is that the variation in rotor torque is higher with the trim controller turned on than when it is turned off. The reason is that the trim controller only reduces the low frequency variations from the quantities that are being controlled and not from those that are not being controlled. In this case, the swashplate actuation required to trim the lift, propulsive force and rolling moment acts to increase the amplitude of rotor torque variations. This effect is seen for each of the two trim control methods and at all wind tunnel speeds tested. The only way to remove the variability in these measurements would be to remove the transients in the wind tunnel flow.

Figure 14 shows time histories for $2 /$ rev IBC phase sweeps with and without trim control. These data were taken at an advance ratio of 0.35 and a lift of about 18,000 pounds. With no trim control (swashplate fixed), there are large changes in the rotor hub forces and moments over the entire range of IBC phase. These changes make it difficult to determine the real effect of IBC actuation on rotor performance. With trim control active, the lift force, propulsive force and rolling moment are held at the desired trim condition throughout the data run. Some spikes are seen in the loads measurements when the IBC phase is changed, particularly in the rolling moment, but the trim controller quickly re-trims the rotor.

The data in Figure 14 also shows that about 1 degree of swashplate collective, and longitudinal and lateral cyclic are required to maintain the rotor trim condition during this particular $2 / \mathrm{rev}$ IBC phase sweep. This would not be a factor in a real flight application as the IBC would be continuously controlled and adapted to the respective flight condition with relatively small changes in the $2 / \mathrm{rev}$ IBC amplitude and phase. These changes would likely not be noticeable to the pilot and could be easily accounted for by the helicopter primary flight control system. It should be noted that the effects of $3 / \mathrm{rev}, 4 / \mathrm{rev}$ and $5 / \mathrm{rev}$ IBC actuation on rotor trim were much smaller than those observed with $2 /$ rev IBC.

The following sections show a validation of the trim control system design and show a comparison between the CONDUIT ${ }^{\circledR}$ analysis with the final tuned control system gains and wind tunnel data. Results include the effects of IBC actuation on rotor dynamics, comparison between the wind tunnel model responses and the FORECAST simulation model responses, and identification of swashplate command scaling and processing delay.

\section{Effects of IBC Actuation on Rotor Dynamic Response}

The effect (if any) that IBC actuation for performance improvement and/or vibration/noise reduction has on the dynamic response of the UH-60A rotor system is important for the operation and performance of the trim control system. To determine how IBC actuation affects the rotor dynamic response, data were collected while dynamically exciting the rotor system through the swashplate at various test conditions with and without IBC actuation. Dynamic excitation was applied as frequency sweep commands individually to the swashplate collective and longitudinal and lateral cyclic pitch inputs. Figure 15 shows an example of the control input and the rotor lift force and pitching moment responses for a baseline collective frequency sweep (no IBC). Two IBC actuation cases were considered during this wind tunnel test. One was representative of an open-loop IBC inputs that gives improvement in performance (2/rev IBC at a specific phase angle). The other was an open-loop IBC input that gives a reduction in vibration (3/rev IBC at a specific phase). Complete sets of frequency sweep records were collected for a low-speed case at an advance ratio of 0.25 (about 108 knots) and a high-speed case at an advance ratio of 0.35 (about 150 knots). 
Figure 16 shows the frequency responses of lift force due to collective, rolling moment due to lateral cyclic, and propulsive force and pitching moment due to longitudinal cyclic for the high-speed case at an advance ratio of 0.35 . These frequency responses were identified using the CIFER ${ }^{\circledR}$ frequency domain system identification tool (Ref. 10). The IBC actuation inputs were $1.5 \mathrm{deg}, 2 / \mathrm{rev}$ actuation at a phase of 210 degrees, and 0.9 degrees, $3 / \mathrm{rev}$ IBC actuation at a phase of 60 degrees. These frequency response comparisons show that there are some slight changes in the frequency responses with IBC actuation, mostly in the magnitude responses at frequencies below about $1 \mathrm{rad} / \mathrm{sec}$. There is also a slight change at about $2 \mathrm{rad} / \mathrm{sec}$ with IBC actuation seen in the responses to collective and longitudinal cyclic. This change at $2 \mathrm{rad} / \mathrm{sec}$ was not seen in the response at an advance ratio of 0.25 . A similar result with slight changes in response magnitude at frequencies below $1 \mathrm{rad} / \mathrm{sec}$ was also seen when examining the frequency responses at the low-speed case at an advance ratio of 0.25 (not shown).

Further analysis is required to determine if the effects of IBC on rotor dynamic response have to be taken into account during the design and optimization of a primary flight control system for a helicopter that includes IBC, however it is not expected that the effects seen here will effect the operation and performance of the trim control system. For this wind tunnel test, the trim controller was operated at a number of different test conditions and with various open- and closed-loop IBC inputs and no effects of IBC actuation on trim controller performance were observed.

\section{Comparison between Simulation Model and Wind Tunnel Model Responses}

Figure 17 shows comparisons between the frequency responses derived from wind tunnel measurements (for the baseline case with no IBC) and those calculated from the Forecast model for the high-speed case. The control inputs for these frequency responses are the actual measured swashplate deflections. It should be noted that these two sets of results are at slightly different speeds with the wind tunnel measurements being collected at an advance ratio of 0.35 (about 150 knots) and the FORECAST results were calculated at 160 knots. These frequency response comparisons show that there is virtually no difference in phase between the wind tunnel and simulation model responses, but there is an under prediction of the response magnitude with the simulation model that is fairly uniform with frequency. The degree to which the frequency response magnitudes are under predicted with Forecast is calculated by taking an average difference over the frequency range from 1.0 to $10 \mathrm{rad} / \mathrm{sec}$. The results for each input/output pair are listed in Table 1 and represent the ratio of the wind tunnel model responses to the simulation model responses.

Table 1: Ratios of wind tunnel model response to simulation model response in each control axis.

\begin{tabular}{cc}
\hline \hline Frequency Response & $\begin{array}{c}\text { Ratio (Wind Tunnel/ } \\
\text { Forecast Model) }\end{array}$ \\
\hline Lift Force / Collective & 1.835 \\
Rolling Moment / Lateral Cyclic & 1.170 \\
Propulsive Force / Longitudinal Cyclic & 1.316 \\
Pitching Moment / Longitudinal Cyclic & 1.758 \\
\hline \hline
\end{tabular}

This under prediction of response sensitivity could indicate that the control derivatives are being under predicted due to some effect of the wind tunnel environment that is not being captured in the FORECAST model. FORECAST has been validated and is accurate for speeds up to 120 knots in free flight (Ref. 7), but has not been validated for generating wind tunnel models and has not been validated at speeds as high as 160 knots. Blade flexibility and non-linear inflow may be important to get a better agreement at these higher speeds. Another source of under-prediction is the loads amplification due to balance and structural resonances that result from mounting the rotor in the wind tunnel (ref. 2). These load amplification effects are not included in the FORECAST model. 
The result of under-predicting the force and moment responses in the CONDUIT analysis is that the calculated gains would be too large, which helps to explain the need to reduce the gain values during gain tuning. To account for the discrepancies between simulation and wind tunnel model responses in the CONDUIT $^{\circledR}$ analysis, the outputs loads from FORECAST are multiplied by the Wind Tunnel / Forecast Model ratios shown in Table 1.

\section{Swashplate Actuator Scaling and Time Delay}

The swashplate control commands from the trim controller were sent over analog channels to the DCC external input channels. These analog commands were scaled to produce 1 degree of swashplate command per volt. An end-to-end check of the control input scaling is made by examining frequency responses between the swashplate commands from the trim controller and the measured swashplate deflection. Figure 18 shows the frequency response between the trim control longitudinal cyclic command and the measured longitudinal cyclic deflection of the swashplate. Examination of the magnitude response indicates that there is a scale factor between the trim control command and swashplate measured response since the magnitude curve is flat and offset from the $0 \mathrm{~dB}$ line. This scale factor is primarily due to inaccuracies in the calibration of the DCC and dynamic actuators to external inputs (from the trim controller) and not errors in the swashplate deflection measurements. The phase curve shows a roll off with increasing frequency, which indicates a time or processing delay in the system.

The values of this control scaling and time delay in the system were calculated by fitting a transfer function to the identified frequency responses. For this frequency response, the transfer function was simply a gain and time delay and the fit for the longitudinal cyclic case is overlaid on the frequency response in Figure 18. Similar frequency responses and transfer functions were identified for the collective and longitudinal cyclic channels with the results summarized in Table 2.

Table 2: Control scaling and time delay.

\begin{tabular}{ccc}
\hline Control Channel & $\begin{array}{c}\text { Control Scaling } \\
\text { (Response / Command) }\end{array}$ & $\begin{array}{c}\text { Time delay } \\
\text { (msec) }\end{array}$ \\
\hline \hline Collective & 0.760 & 46.8 \\
Lateral Cyclic & 0.896 & 39.7 \\
Longitudinal Cyclic & 1.204 & 44.8 \\
\hline \hline
\end{tabular}

The effect of the additional $40-45 \mathrm{msec}$ of time delay is to slow the dynamic response of the rotor system and reduce the performance of the trim controller. The control scaling changes the control sensitivities.

\section{CONDUIT Analysis of Final Trim Control Gains}

A CONDUIT $^{\circledR}$ analysis of the final control law gains was performed to check the performance of the final control system configuration. For trim control mode 2 at high-speed, the final gains that produced the best performed in the wind tunnel were set at $60 \%$ of the initial gain values. Table 3 lists the initial and final 'tuned' control law gains, and compares the control crossover frequencies and disturbance rejection characteristics from the initial CONDUIT ${ }^{\circledR}$ control system design and optimization with a final CONDUIT $^{\circledR}$ analysis. This final CONDUIT ${ }^{\circledR}$ analysis includes the FORECAST model correction factors listed in Table 1, the control input scaling and time delay results listed in Table 2, and a notch filter at the progressive lag mode frequency $(5.67 \mathrm{~Hz})$. 
Table 3: Comparison between initial and final 'tuned' control law gains and control system performance characteristics (trim control mode 2 at high-speed).

\begin{tabular}{ccc}
\hline \hline Gain & Initial Gains & Final Tuned Gains \\
\hline Lift Integral & 1.380 & 0.828 \\
Lift Proportional & 0.139 & 0.083 \\
Lift Derivative & 0.120 & 0.072 \\
Rolling Moment Integral & 1.331 & 0.799 \\
Rolling Moment Proportional & 0.221 & 0.133 \\
Rolling Moment Derivative & 0.113 & 0.068 \\
Propulsive Force Integral & 1.673 & 1.004 \\
Propulsive Force Proportional & 0.323 & 0.194 \\
Propulsive Force Derivative & 0.217 & 0.130 \\
Cross-feed - Longitudinal Cyclic to & 5.0 & 3.0 \\
Collective & & \\
Lift Crossover Freq & & $1.06 \mathrm{rad} / \mathrm{sec}$ \\
Rolling Moment Crossover Freq & $1.64 \mathrm{rad} / \mathrm{sec}$ & $0.82 \mathrm{rad} / \mathrm{sec}$ \\
Propulsive Force Crossover Freq & $1.33 \mathrm{rad} / \mathrm{sec}$ & $1.32 \mathrm{rad} / \mathrm{sec}$ \\
& & \\
Lift Disturbance Bandwidth & $1.04 \mathrm{rad} / \mathrm{sec}$ & $0.85 \mathrm{rad} / \mathrm{sec}$ \\
Lift Disturbance Peak & $2.15 \mathrm{~dB}$ & $2.82 \mathrm{~dB}$ \\
Roll Disturbance Bandwidth & $1.04 \mathrm{rad} / \mathrm{sec}$ & $0.67 \mathrm{rad} / \mathrm{sec}$ \\
Roll Disturbance Peak & $2.56 \mathrm{~dB}$ & $2.03 \mathrm{~dB}$ \\
Prop Force Disturbance Bandwidth & $1.04 \mathrm{rad} / \mathrm{sec}$ & $0.96 \mathrm{rad} / \mathrm{sec}$ \\
Prop Force Disturbance Peak & $2.36 \mathrm{~dB}$ & $3.70 \mathrm{~dB}$ \\
& & \\
\hline \hline
\end{tabular}

The largest difference between the initial and final configurations is in the performance of the roll axis. The rolling moment crossover frequency and disturbance rejection bandwidth are significantly lower for the final configuration than the initial configuration. This indicates that the roll channel gains could be increased to get better performance in the roll axis. Another difference is in the propulsive force disturbance rejection peak that is $3.7 \mathrm{~dB}$ for the final configuration compared with $2.36 \mathrm{~dB}$ for the initial gains.

Figure 19 shows the power spectra for the propulsive force (left) and rolling moment (right) for trim with and without the trim controller and is a validation of the disturbance rejection characteristics of the trim control system. The drop in magnitude at low frequency with the trim controller active indicates that the trim controller is effective in reducing the low frequency variability in these quantities. The point at which the power spectra with and without trim control cross is between 1 and $2 \mathrm{rad} / \mathrm{sec}$ for both the propulsive force and rolling moment responses. This is consistent with the disturbance rejection bandwidth values of $0.96 \mathrm{rad} / \mathrm{sec}$ for the propulsive force loop and $0.67 \mathrm{rad} / \mathrm{sec}$ for the rolling moment loop as listed in Table 3.

This validation indicates that the final CONDUIT ${ }^{\circledR}$ analysis is an accurate representation of the performance of the final trim controller configuration.

\section{Summary and Conclusions}

An automatic rotor trim control system was developed and successfully used during the UH-60 IBC wind tunnel test. The trim control system allowed rotor trim to be set more quickly, precisely and repeatable 
than in previous wind tunnel tests, and allowed the rotor trim state to be maintained during transients and drift in wind tunnel flow, and through changes in IBC actuation. This ability to maintain a consistent rotor trim state was a key factor to enable the effects of IBC on rotor performance, vibration, noise and loads to quickly and accurately evaluated. The key conclusions from the development and operation of the trim control system are:

- Both trim control methods developed for this wind tunnel test were effective at accurately trimming the rotor and holding the rotor trim through transients in wind tunnel flow and IBC actuation. The shaft fixed controller with direct propulsive force control was more time efficient and was used for the majority of research data collection.

- Two gain sets for each of the two trim control modes were sufficient to cover the entire wind tunnel test envelope of tunnel speeds and rotor loading conditions. One gain set was used for high-speeds (above 120 knots) and the other was used for low-speeds (below 120 knots).

- Direct propulsive force control through longitudinal cyclic pitch proved to be challenging since propulsive force is not the primary response to longitudinal cyclic and requires changes in rotor longitudinal flapping, which introduces delay. In addition, a notch filter had to be included in the propulsive force feedback channel due to a coupling that was observed between the fixed-frame progressive lag mode and propulsive force.

\section{References}

[1] Norman, T.R., Theodore, C.R., Shinoda, P., Fuerst, D., Arnold, U.T.P., Makinen, S., Lorber, P., and O'Neill, J., "Full-Scale Wind Tunnel Test of a UH-60 Individual Blade Control System for Performance Improvement and Vibration, Loads and Noise Control," American Helicopter Society $65^{\text {th }}$ Annual Forum, Grapevine, TX, May 27-29, 2009.

[2] Norman, T.R., Shinoda, P., Kitaplioglu, C., Jacklin, S.A., and Sheikman, A., "Low-Speed Wind Tunnel Investigation of a Full-Scale UH-60 Rotor System," American Helicopter Society $58^{\text {th }}$ Annual Forum, Montreal, Canada, June 11-13, 2002.

[3] Jacklin, S.A., Haber, A., deSimone, G, Norman, T.R., Kitaplioglu, C., Shinoda, P., "Full-Scale Wind Tunnel Test of an Individual Blade Control System for a UH-60 Helicopter," American Helicopter Society $58^{\text {th }}$ Annual Forum, Montreal, Canada, June 11-13, 2002.

[4] Lorber, P.F., Park, C., Polak, D., O’Neill, J., and Welsh, W., "Acitve Rotor Experiments at Mach Scale Using Root Pitch IBC," American Helicopter Society $51^{\text {st }}$ Annual Forum, Fort Worth, TX, May 9-11, 1995.

[5] Haber, A., Jacklin, S.A., and deSimone, G., "Development, Manufacturing, and Component Testing of an Individual Blade Control System for a UH-60 Helicopter Rotor," American Helicopter Society Aerodynamics, Acoustics, and Test and Evaluation Technical Specialists Meeting, San Francisco, CA, January, 2002.

[6] Tischler, M. B., et al, "A Multidisciplinary Flight Control Development Environment and Its Application to a Helicopter," IEEE Control Systems Magazine, Vol. 19, No. 4, pg. 22-33, August, 1999. 
[7] Kim, F.D., Celi, R., and Tischler, M.B., "High Order State Space Simulation Model of Helicopter Flight Mechanics," Journal of the American Helicopter Society, Vol. 38, N0. 2, October 1993.

[8] Mansur, H.M., Lusardi, J.A., Tischler, M.B., and Berger, T., “Achieving the Best Compromise between Stability Margins and Disturbance Rejection Performance," American Helicopter Society $65^{\text {th }}$ Annual Forum, Grapevine, TX, May 27-29, 2009.

[9] Blanken, C.L., Hoh, R.H., Mitchell, D.G., and Key, D.L., “Test Guide for ADS-33E-PRF,” U.S. Army RDECOM Special Report AMR-AF-08-07, July 2008.

[10] Tischler, M.B., and Remple, R.K., "Aircraft and Rotorcraft System Identification: Engineering Methods With Flight Test Examples," AIAA, 2006. 


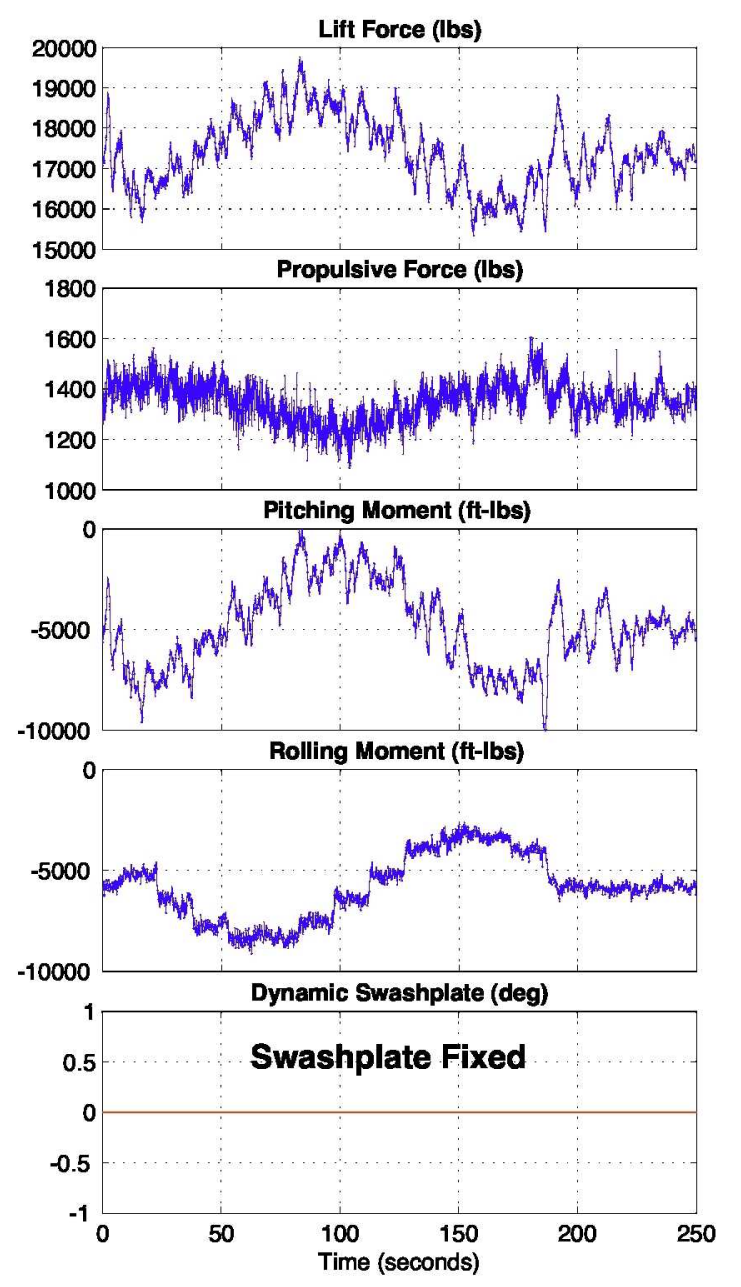

Figure 1: Example time history data for $2 / \mathrm{rev}$ (1 degree amplitude) IBC phase sweep. Advance ratio $=0.35, \mathrm{C}_{\mathrm{L}} /$ sigma $=0.077$.

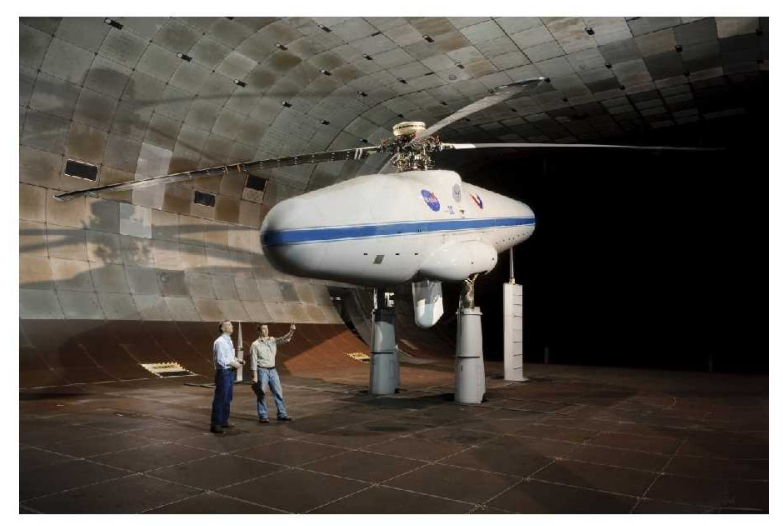

Figure 3: UH-60A rotor system installed in the National Full-Scale Aerodynamics Complex (NFAC) 40- by 80 -foot wind tunnel.

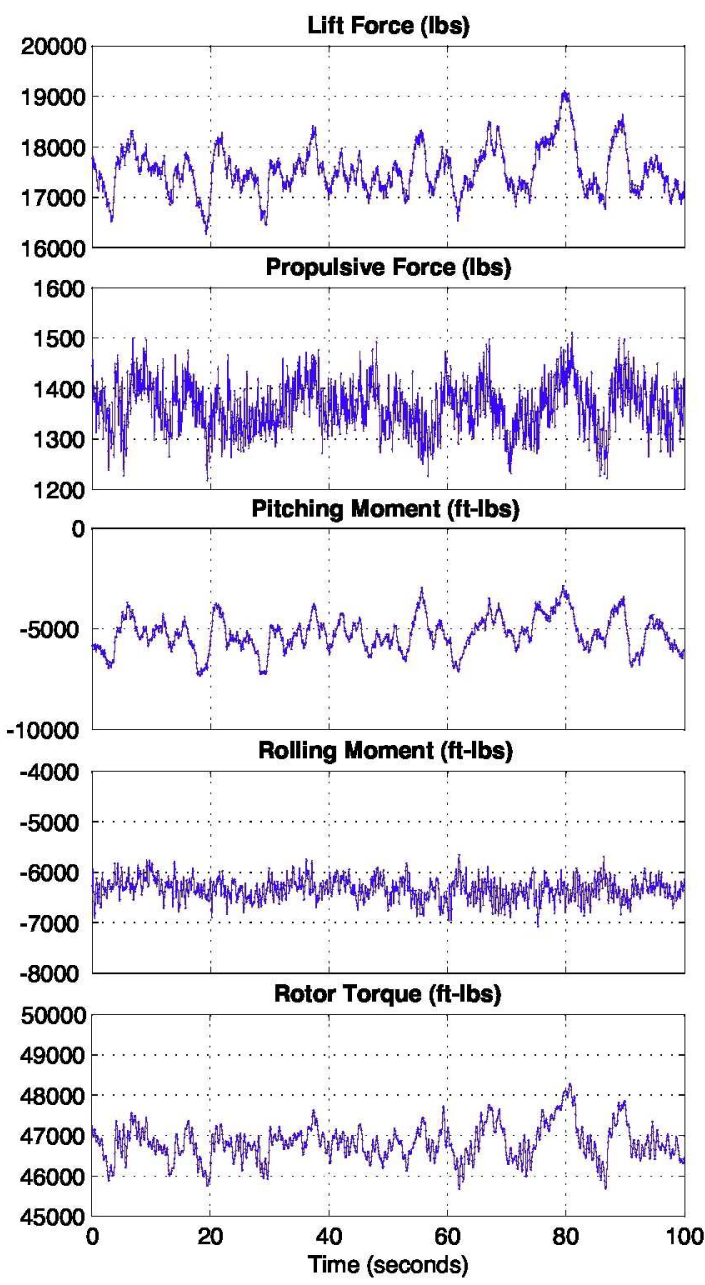

Figure 2: Example time history data with the swashplate fixed and no IBC actuation. Advance ratio $=0.35, \mathrm{C}_{\mathrm{L}} /$ sigma $=0.077$.

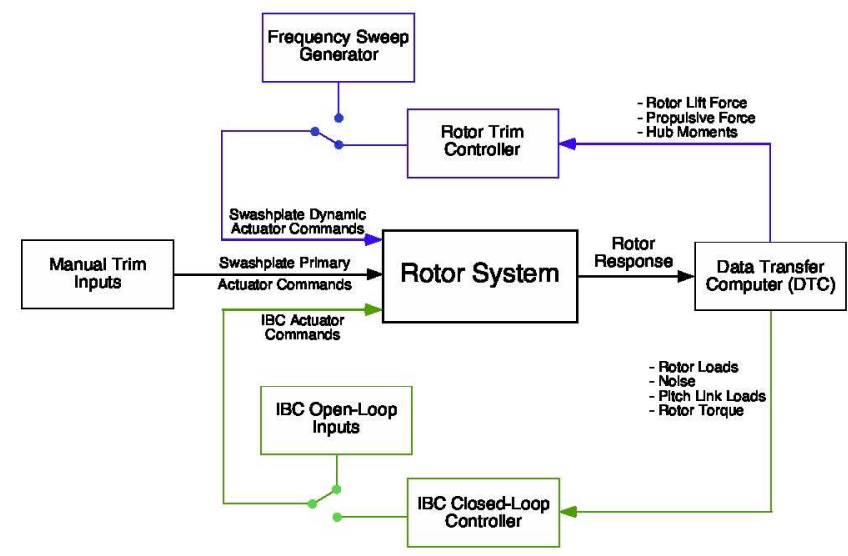

Figure 4: Simplified block diagram of three rotor blade pitch control systems. 


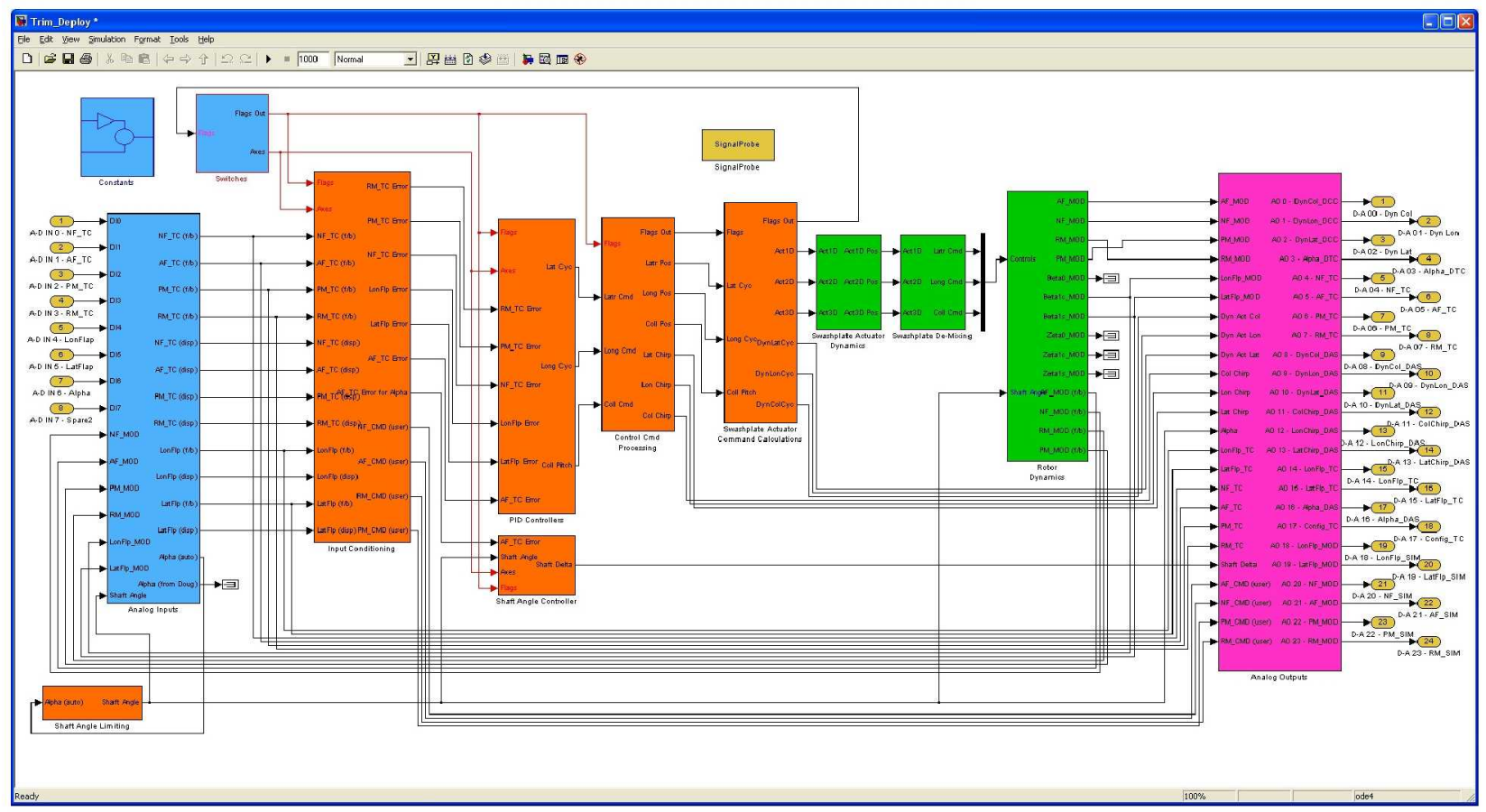

Figure 5: Block diagram of trim controller written in Matlab SimuLink.
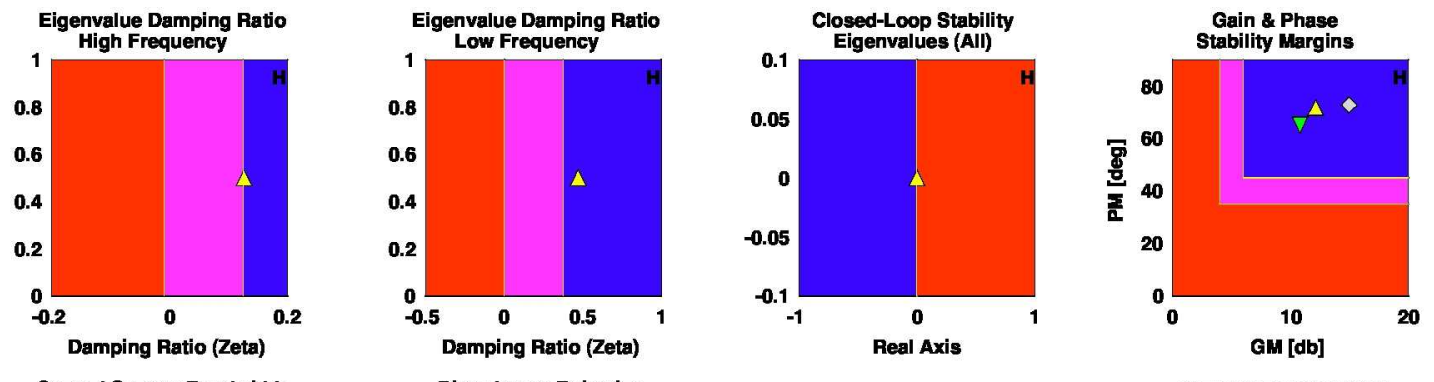

Control System Bandwidth
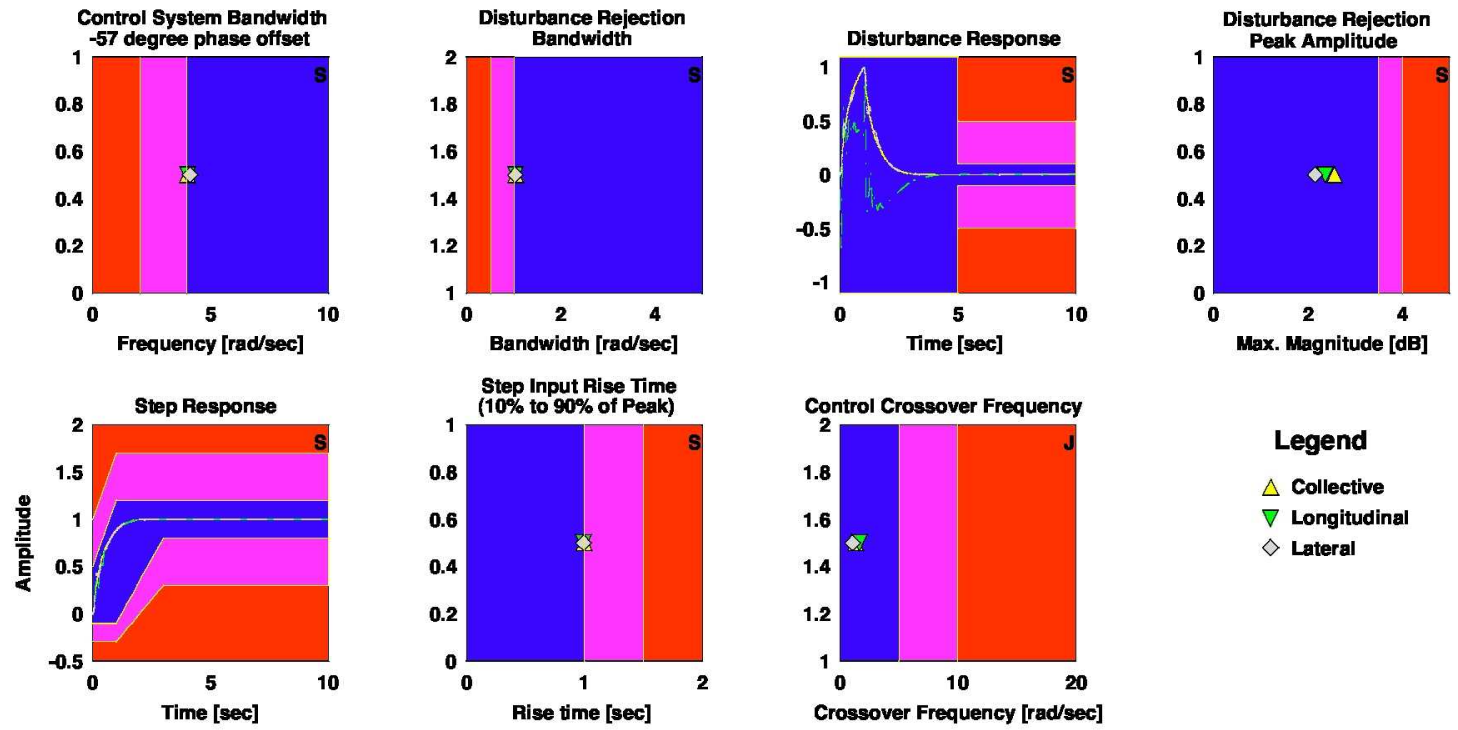

Legend

$\triangle$ Collective

$\nabla$ Longitudinal

$\diamond$ Lateral

Figure 6: Example handling qualities window from CONDUIT for high-speed case (160 knots, 18,000 lbs lift) and trim control mode 2. 


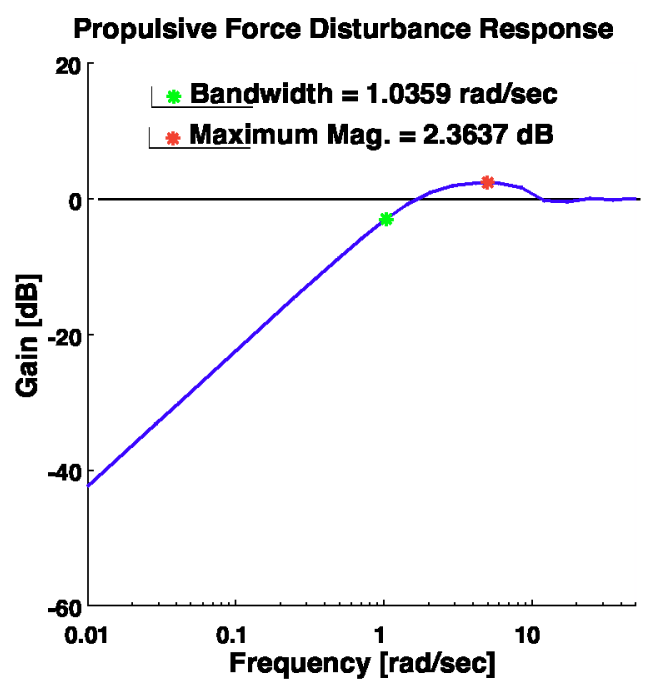

Figure 7: Propulsive force disturbance rejection bandwidth and maximum magnitude plot (simulation).

\section{Top View}
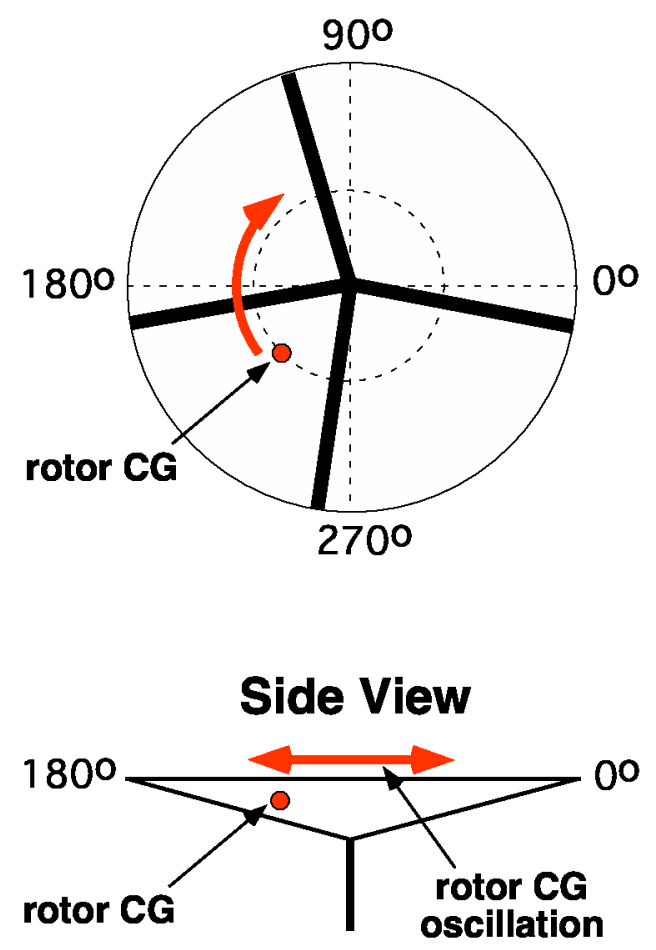

Figure 9: Excitation of lag fixed-frame degrees of freedom cause a rotation of the center of gravity of the rotor that couples with the propulsive force.

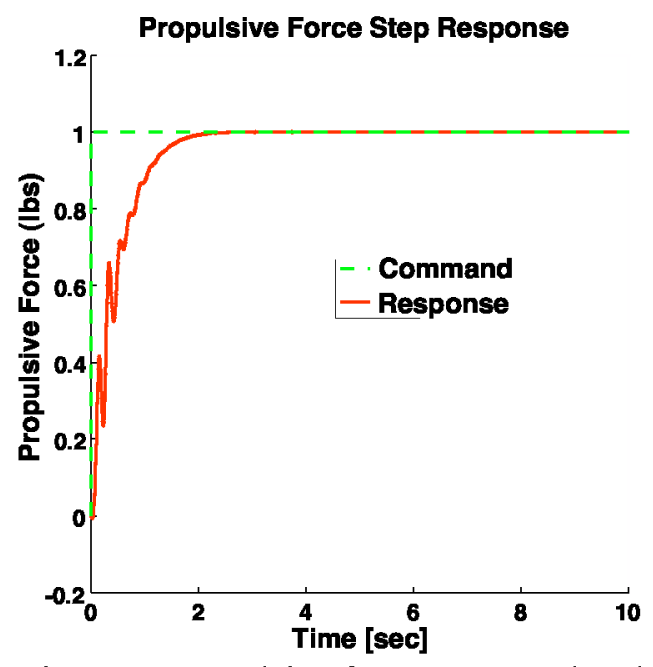

Figure 8: Propulsive force command and response for step input (simulation). Note excitation of lightly damped progressive lag mode in step response.

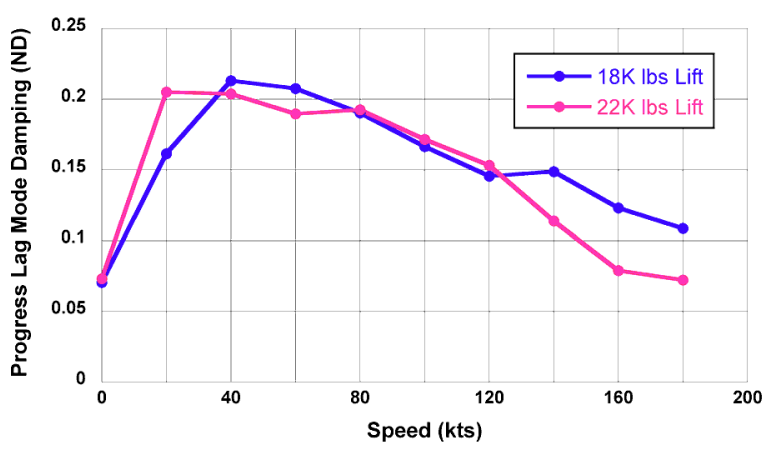

Figure 10: FORECAST prediction of progressive lag mode damping versus speed. The frequency of this mode varies between 31 and $35 \mathrm{rad} / \mathrm{sec}(4.93$ and $5.57 \mathrm{~Hz})$. 


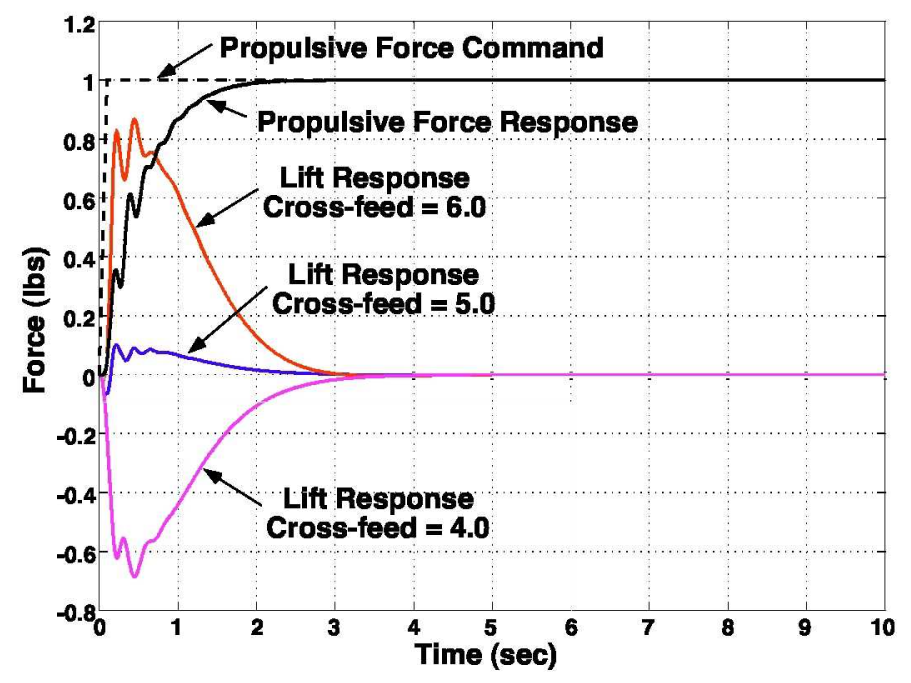

Figure 11: Closed-loop time history for step input of propulsive force with various cross-feed values (simulation). Blue line shows lift response with a final cross-feed value of 5.0.

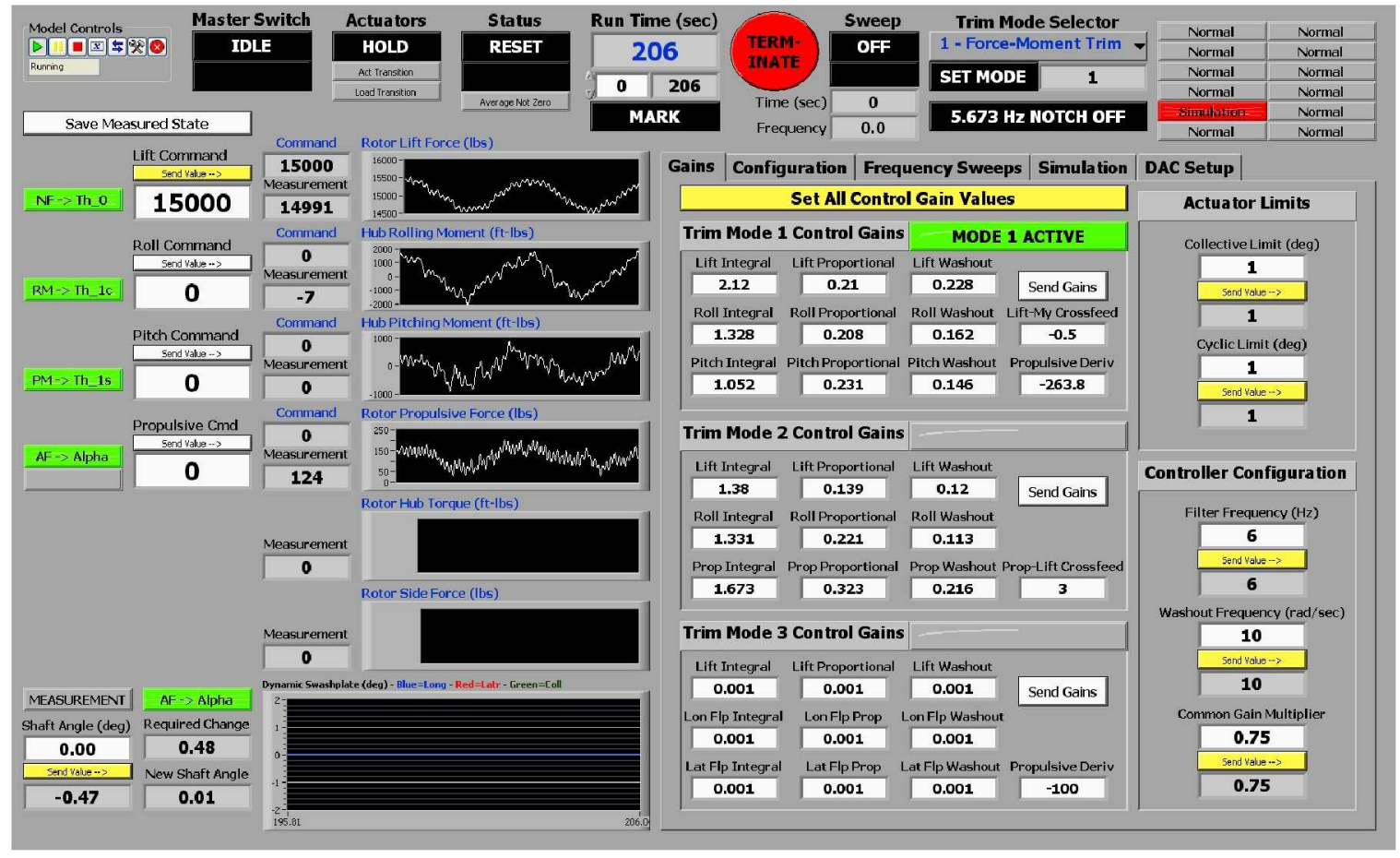

Figure 12: Trim Controller operator interface written in National Instruments Labview. 

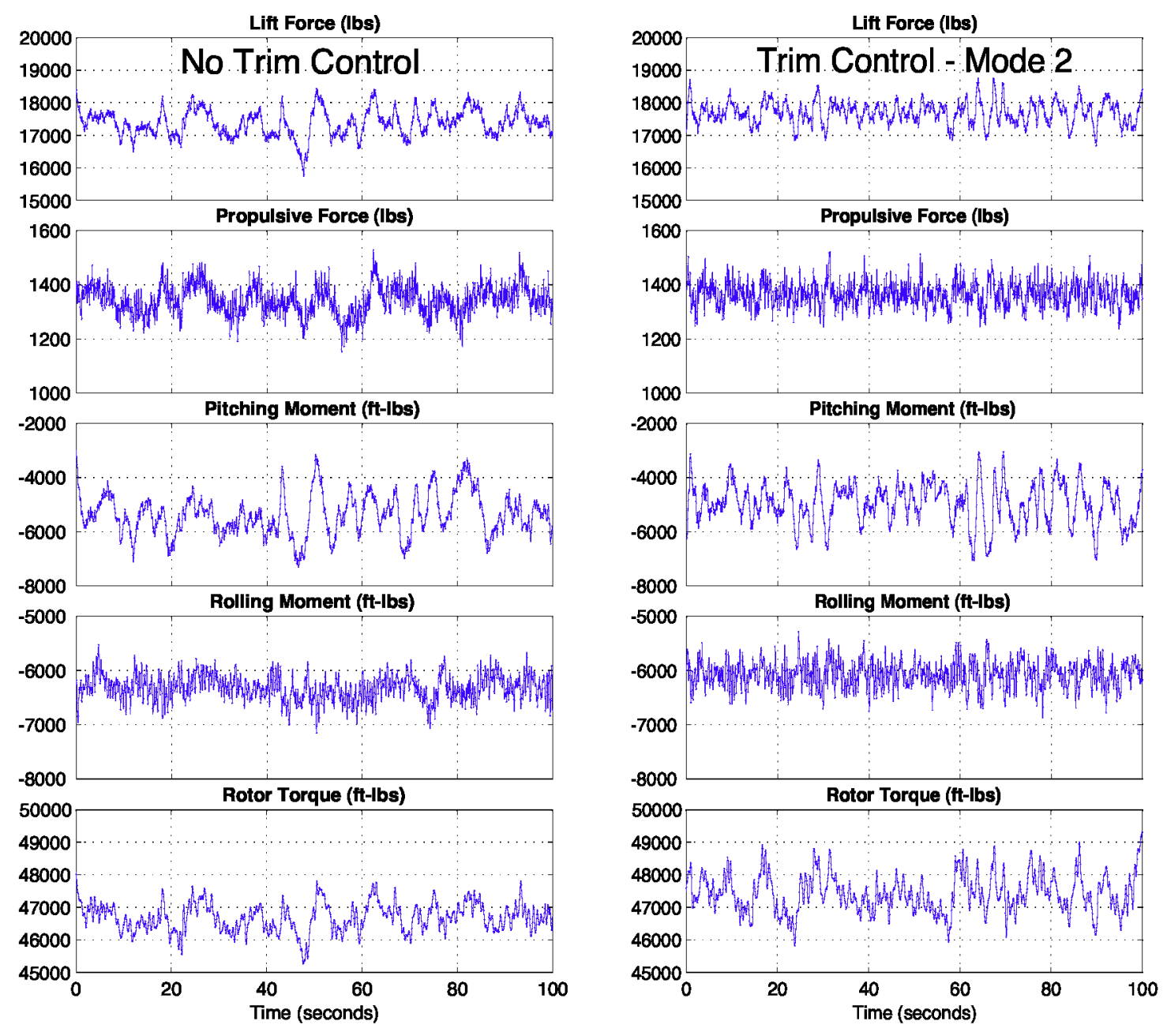

Figure 13: Time histories without trim control (left) and with trim control operating in mode 2 (right). Advance ratio $=0.35, \mathrm{C}_{\mathrm{L}} /$ sigma $=0.077$, no $\mathrm{IBC}$ actuation. 

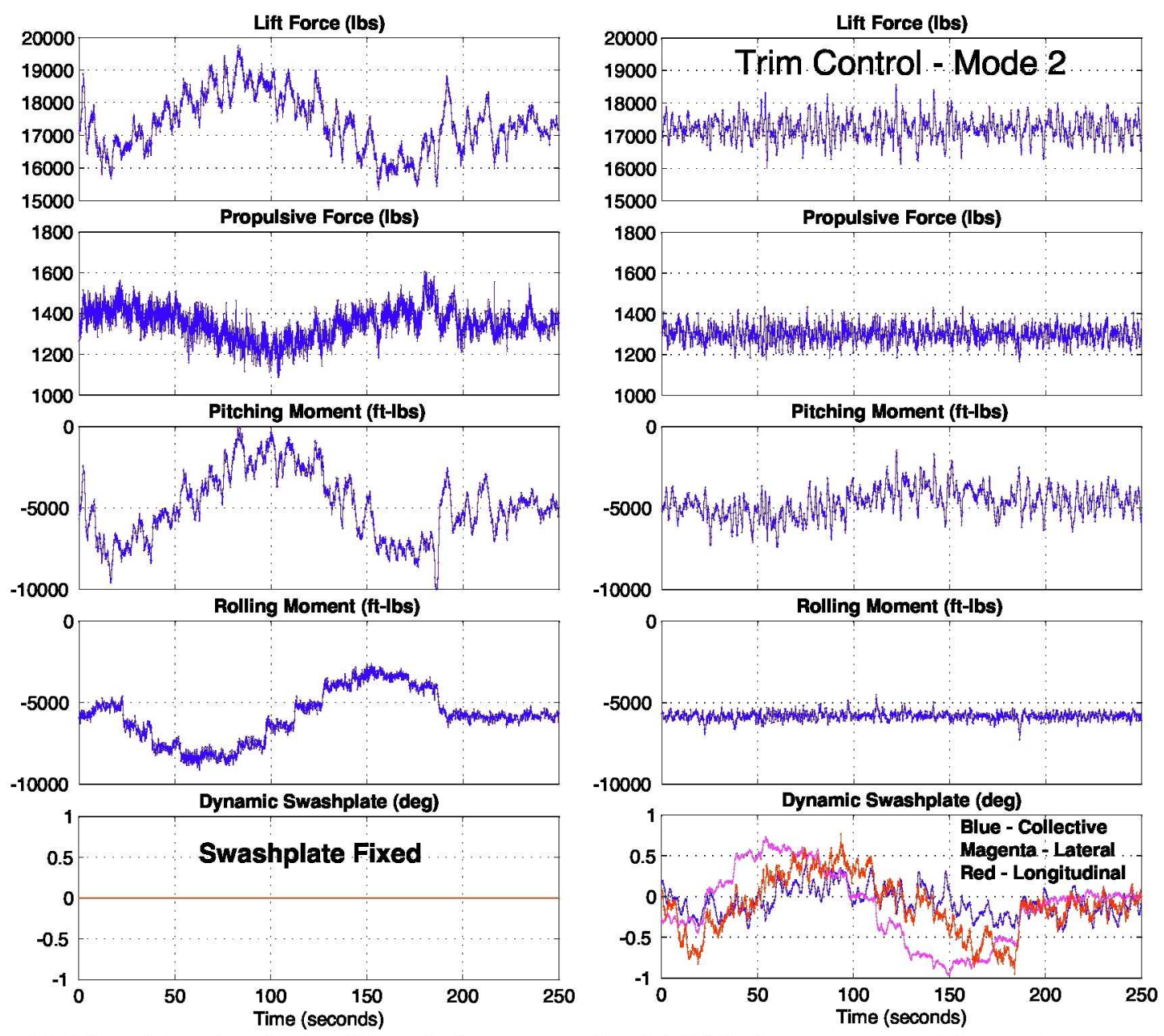

Figure 14: Time histories during 2/rev ( 1 degree amplitude) IBC phase sweeps with no trim control (left) and trim control active in mode 2 (right). Advance ratio $=0.35, \mathrm{CL} / \mathrm{sigma}=0.077$.
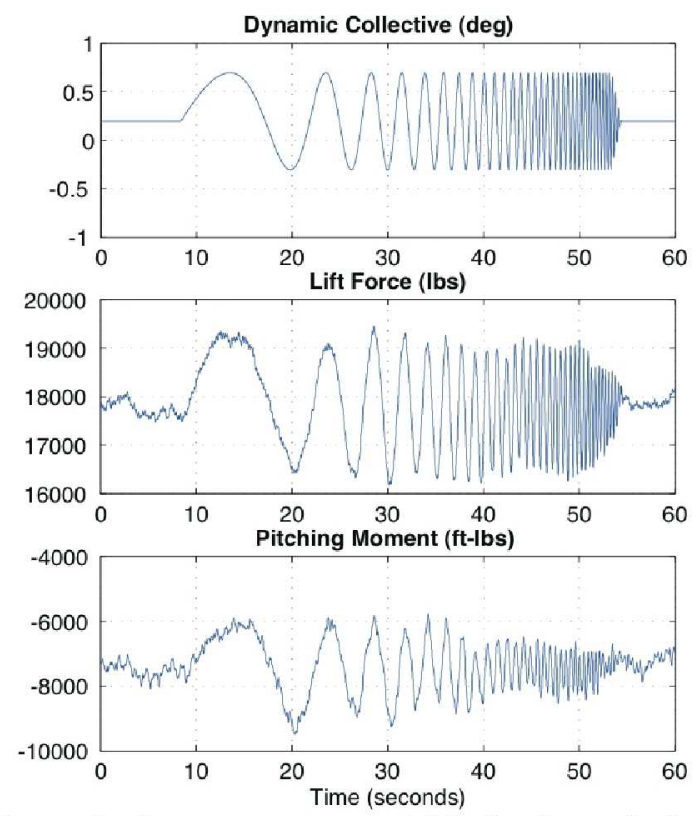

Figure 15: Example frequency sweep (chirp) of swashplate collective. 

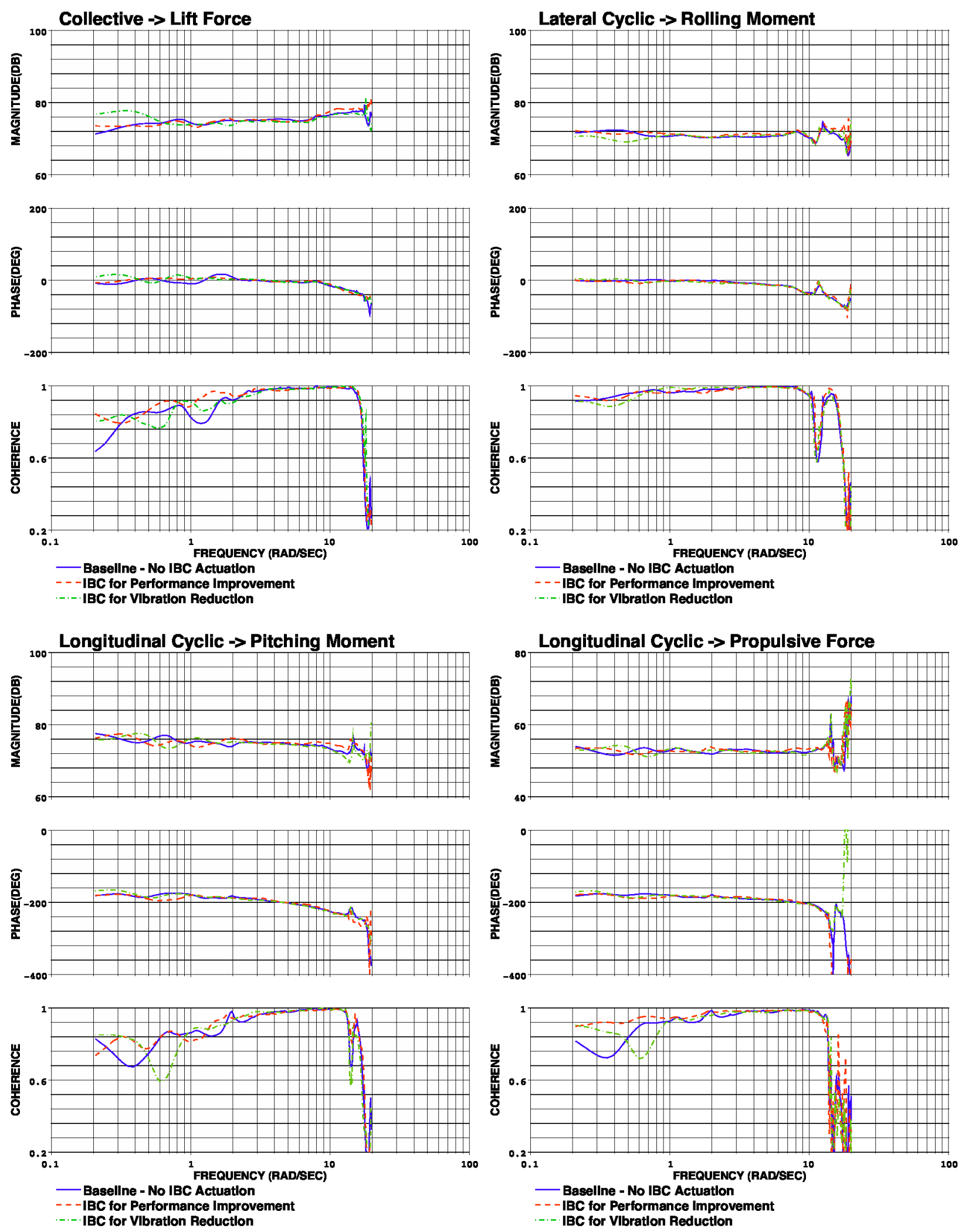

Figure 16: Effect of IBC for performance and vibration on rotor dynamics response at high speed. Advance ratio $=0.35, \mathrm{C}_{\mathrm{L}} / \mathrm{sigma}=0.077$. 

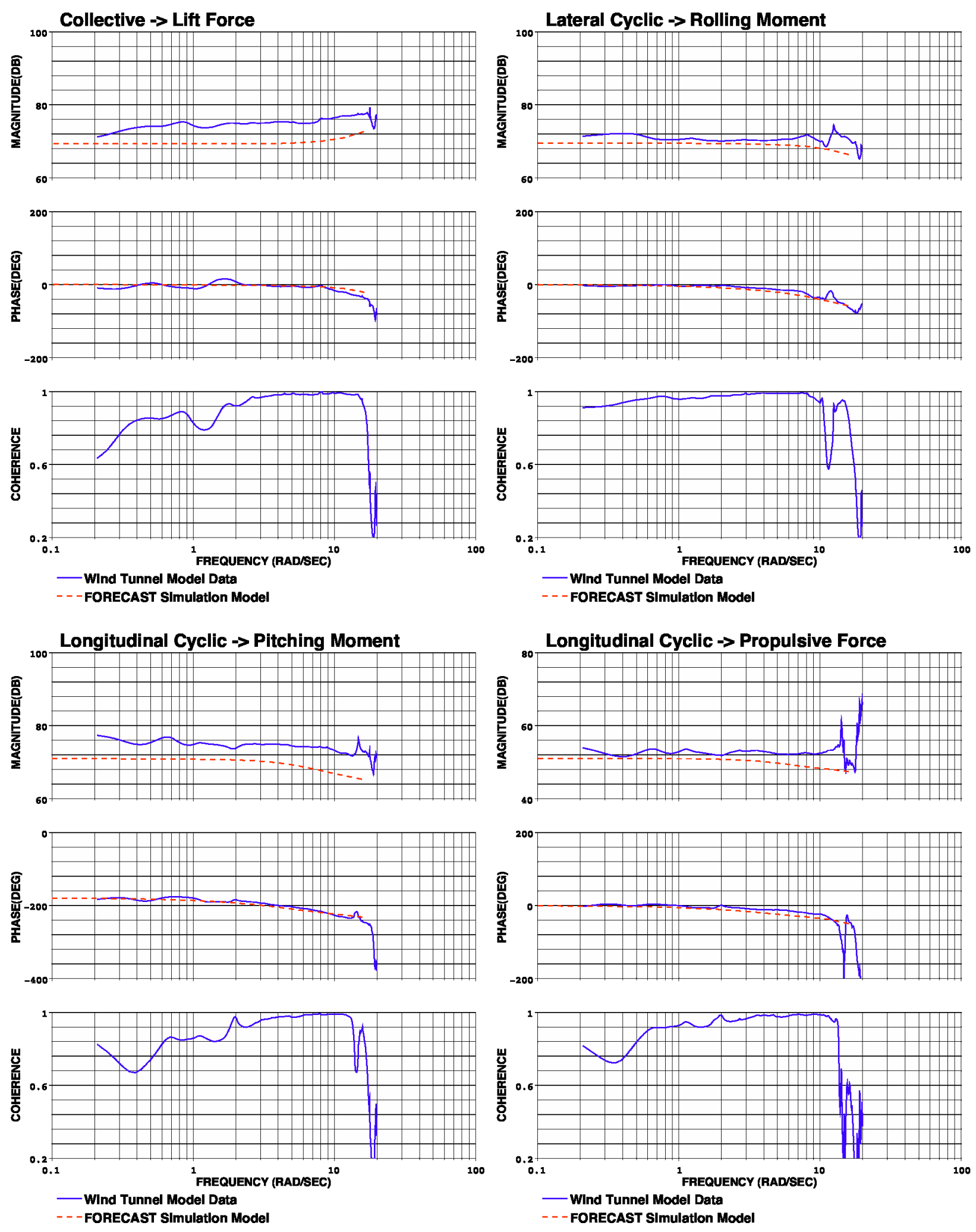

Figure 17: Comparison between wind tunnel model and FORECAST linear model frequency responses. Advance ratio $=0.35, \mathrm{C}_{\mathrm{L}} /$ sigma $=0.077$, no $\mathrm{IBC}$ actuation. 

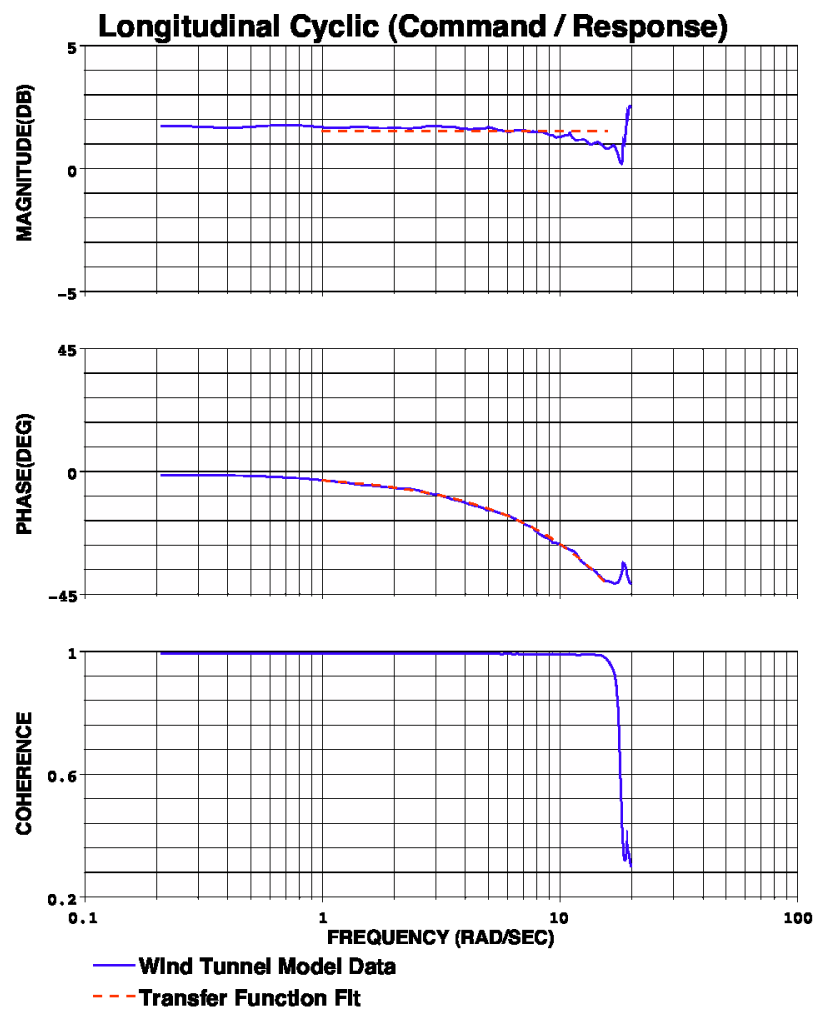

Figure 18: Frequency response of longitudinal cyclic measured response due to command from the trim controller and transfer function fit with a gain and time delay.
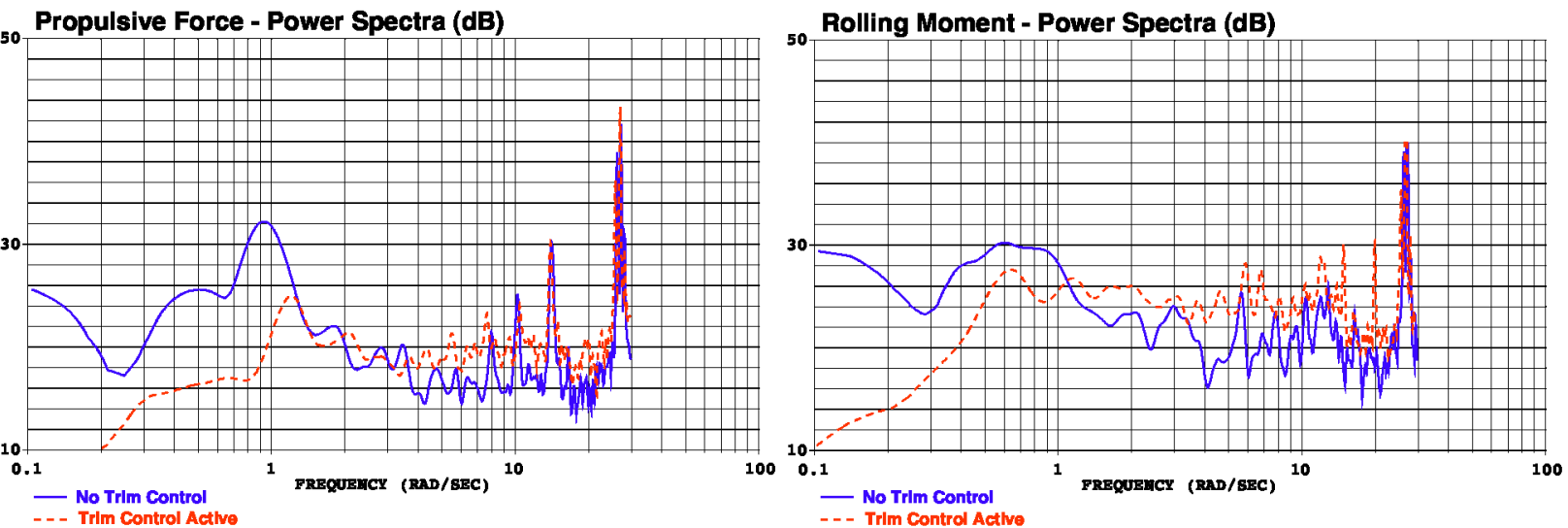

Figure 19: Power spectra for propulsive force (left) and rolling moment (right) without trim control (solid line) and with trim control in mode 2 (dashed line). Advance ratio $=0.35, \mathrm{C}_{\mathrm{L}} / \mathrm{sigma}=0.077$, no $\mathrm{IBC}$ actuation. 